Arch. Met. Geoph. Biokl., Ser. A, 20, 43-53 (1971)

(C) by Springer-Verlag 1971

$551.574 .42: 551.579 .5$

Department of Geography, University of Michigan, Ann Arbor, Michigan, U.S.A.

\title{
Field Observations of Soil Temperature and Water Tension Feedback Effects on Needle Ice Nights
}

\author{
Sam I. Outcalt
}

With 6 Figures

Received January 14, 1971

\section{Summary}

Numerous laboratory studies have indicated that thermal gradients may produce appreciable soil water movement in the absence of a strong suction field. In addition the soil water flow and thermal properties are physically interrelated. This paper presents field data taken during needle ice events at Vancouver, Canada, and yields an indication of the magnitude of interaction between the thermal and water flow properties. This feedback determines the state of soil frost hazard in a location where damage to plant material is produced by ice needle growth. Further apparently anomalous interruption in the normal parabolic temperature-time pattern during radiation events is interpreted as the product of water flow down a thermal gradient.

\section{Zusammenfassung}

Beobachtungen des Rückkopplungseffektes von Bodentemperatur und Wasserspannung auf die nächtliche Bildung von Eisnadeln

Zahlreiche Laboratoriumsstudien deuteten darauf hin, daß thermische Gradienten selbst bei Abwesenheit starker Saugkräfte bedeutsame Wasserbewegungen im Boden hervorrufen können. Überdies stehen die Strömung des Bodenwassers und die thermischen Eigenschaften des Bodens damit in physikalischem Zusammenhang. Die vorliegende Arbeit enthält Meßdaten, die während der Bildung von Nadeleis in Vancouver, Kanada, gewonnen wurden und größenordnungsmäßige Beziehungen zwischen Wärme- und Wasserstrom im Boden angeben. Die Rückkopplung zwischen den beiden Strömen bestimmt die Bodenfrostgefahr an Orten, wo Pflanzenschäden durch Eisnadelbildung hervorgerufen werden. Eine offensichtlich abnormale Unterbrechung des normalen Temperatur-Zeit-Verhältnisses während des Ausstrahlungsvorganges wird als Effekt der Wasserströmung entsprechend einem thermischen Gradienten interpretiert. 


\section{Introduction}

During the winter of $1967 / 68$ mercury manometer observations of soil water tension were carried out as part of a study of needle ice growth in a bare sandy-loam field at Vancouver, Canada. Needle ice is a near surface type of segregation ice which forms during diurnal frost events in wet medium textured soils [10]. These data, in conjunction with other micrometeorological and soil-physical data, indicate the extreme complexity of the diurnal frost environment which results from feedback between the thermal and water flow properties of the near surface soil.

\section{The Tensiometer}

The instrument is basically a mercury manometer which is in hydraulic contact with the soil water. In all respects, except the mode of contact, it is similar to other units for water tension measurement. In this unit the contact between the soil water and the

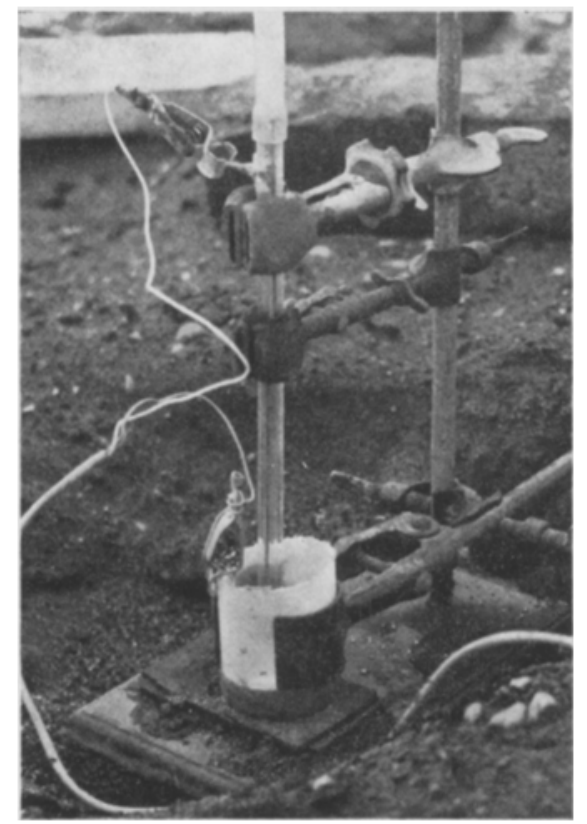

Fig. 1. The Mercury Manometer Resistance Slidewire Unit

de-aired water in the tensiometer system is maintained through a paste of $29 \mu$ spherical class beads placed in a plastic holder and connected to the manometer through a fine porous nylon ("milli- 
pore") membrane [4]. These units have low impedence and have a tension range from $0-150 \mathrm{~mm} \mathrm{Hg}$., the upper limit being the air intrusion value for the membrane composite. In the field the glass bead holder has a contact area of roughly $4 \mathrm{~cm}^{2}$ in a vertical plane yielding a mean tension for a $2 \mathrm{~cm}$ layer of soil. Tension can be recorded by using the mercury as a sliding contact in one arm of a resistance bridge (see Fig. 1). The unit is calibrated by placing the sensing head in a water bath and lifting the mercury reservoir to varied elevations as the recorder deflection is noted. The major difficulty with the system is freezing of the water in the tensiometer during prolonged sub-freezing periods. This limits the application of the system to short light-frost events.

\section{The Observations}

A typical plot of soil surface displacement (heave) and water tension in the $4-6 \mathrm{~cm}$ layer is illustrated in Fig. 2. This figure demonstrates the rapid increase in tension produced by segregation (needle

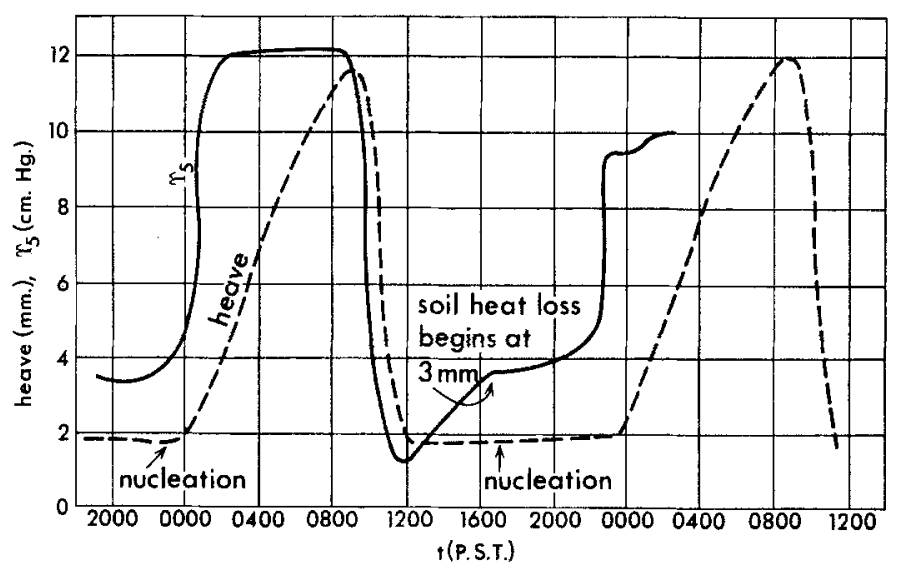

Fig. 2. Heave and Soil Water Tension, February 6-8, 1968

growth) and the sudden drop in tension as the ablation of the needles during the pre-noon hours saturates the upper soil layers with meltwater prior to the structural failure of the needles (descent of the heave meter). Fig. 3 illustrates the frequently observed decrease in tension (increase in soil water content) which occurs during the late-afternoon early-evening hours on cold-clear nights prior to nucleation. 


\section{Analysis}

During the field investigations two persistant time dependent patterns were recognized. These were the reduction of soil water tension near or after sunset and the tension increase associated with the ice segregation (needle growth-heave) process. Both phenomena occur during clear weather radiation cooling events. During the early afternoon hours the soil water tension is high as evaporation is normal with the clear-cold-dry anticyclonic weather which produces needle ice events at Vancouver [11]. During evaporation the
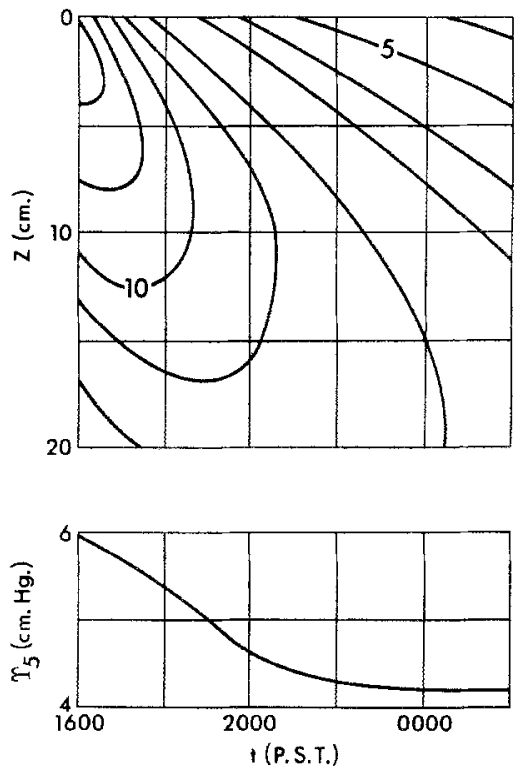

Fig. 3. Time Dependent Variation of Soil Temperature Isotherms $\left({ }^{\circ} \mathrm{C}\right)$ and Water Tension, February 26-27, 1968

tension and temperature (saturation vapor pressure) gradients are opposed, the tension gradient being directed toward the surface whereas the thermal gradient is directed into the soil. Vertical soil water movement is governed by both of these gradients [2]. As the surface begins to cool, when the radiation balance just matches the turbulent heat flux toward the surface, the tension and thermally driven components are both directed toward the soil surface. As the cooling soil surface temperature approaches the dew point, evaporation decreases thereby producing a buildup of soil water flowing down the thermal gradient toward the cool surface. The net effect is a tendency of decreasing soil water tension in the near surface soil 
beginning just prior to sunset. If nucleation and ice segregation occur, the soil freezing plane will remain at a fixed depth causing a rapid tension climb at the onset of soil heave (see Fig. 2).

\section{Soil Cooling Rates}

The nocturnal surface temperature regime can be broken into four distinct phases which are illustrated as in Fig. 4. Brunt cooling is the predominantly radiation cooling process during which the temperature drop from an initial temperature $\left(T_{i}\right)$ varies directly with the square root of elapse time $(t)$ and the soil heat flux toward the surface $\left(S_{0}\right)$, which approaches the net radiation balance $\left(B_{0}\right)$ under calm con-

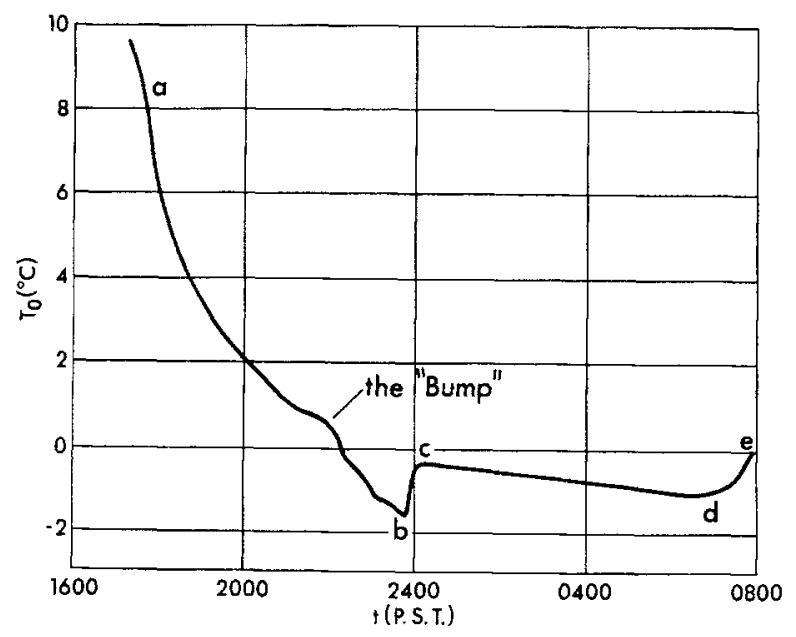

Fig. 4. Soil Surface Cooling, March 4-5, 1967

$a-b$ Brunt Cooling, $b$ Nucleation, $b-c$ Undercooling, $c$ Soil Water Freezing Point, $c-d$ Needle Ice Growth, $d-c$ Warming by Beam Radiation

ditions, and varies inversely with the soil "thermal admittance" $\left(C_{s} V \alpha_{s}\right)$ which is the product of the volumetric heat capacity and the square root of the thermal diffusivity [8]. The relationship is expressed as Eq. (1) [1].

$$
T-T_{i} \cong \frac{2}{\sqrt{\pi}} \frac{B_{0} \sqrt{t}}{C_{s} \sqrt{\alpha_{s}}}
$$

where $B_{0} \rightarrow-S_{0}$ as wind velocity decreases. An empirical form of Brunt's cooling rule has the following form.

$$
T-T_{i}=m \sqrt{t}
$$


Here the empirical cooling slope $(m)$ is a function of both soil water content and the heat flux toward the soil surface which is in turn a function of both net radiation and the rate of the turbulent heat transfer to the air. Some $m$-values calculated between 1600PST and nucleation during an extended series of similar clear needle ice nights are presented in Table 1 . These values were obtained by the method of least squares in which the coefficients of determination in all fits were over $97 \%$.

Table 1. Values of $m$ During February 1968

\begin{tabular}{|c|c|c|c|c|c|}
\hline Date & $\mathrm{m}\left({ }^{0} \mathrm{C} \mathrm{hr} .{ }^{-1 / 2}\right)$ & Std Error $\left({ }^{\circ} \mathrm{C}\right)$ & Date & $\mathrm{m}\left({ }^{0} \mathrm{C} \mathrm{hr} .{ }^{-1 / 2}\right)$ & Std. Error $\left({ }^{\circ} \mathrm{C}\right)$ \\
\hline $5-6$ & 2.7 & 0.6 & $12-13$ & 4.5 & 0.5 \\
\hline $6-7$ & 2.6 & 0.4 & $13-14$ & 3.8 & 0.8 \\
\hline $7-8$ & 3.9 & 0.4 & $14-15$ & 4.5 & 0.6 \\
\hline $8-9$ & 3.9 & 0.4 & $15-16$ & 4.7 & 0.9 \\
\hline $9-10$ & 3.2 & 0.4 & $16-17$ & 5.0 & 0.1 \\
\hline $10-\mathrm{I} 1$ & 3.1 & 0.6 & & & \\
\hline $11-12$ & 3.8 & 0.4 & & & \\
\hline
\end{tabular}

Note the ratio of the maximum value of $m$ to the minimum value is approximately 1.9. Desorption testing with a porous plate (see Fig. 5) indicated that within the observed soil water tension range

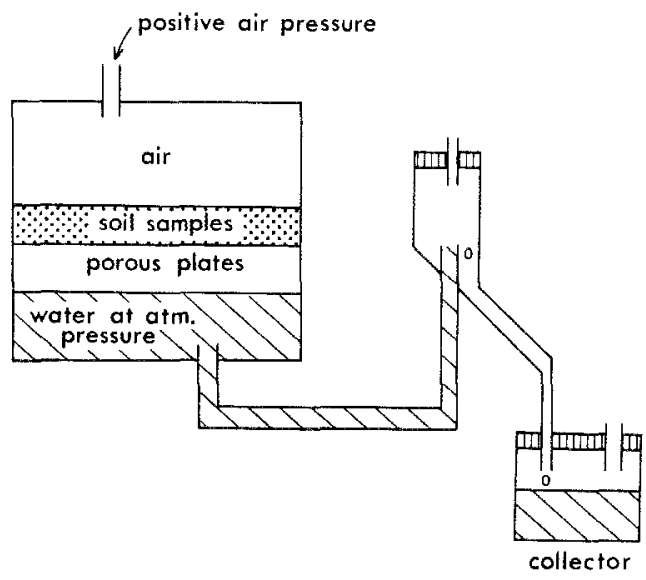

Fig. 5. Schematic Diagram of Porous Plate Extractor

of $0-120 \mathrm{~mm} \mathrm{Hg}$. the volumetric water content decreased from $38 \%$ to $26 \%$. Assuming only mineral soil $\left(X_{m}\right)$ and water volume fractions $\left(X_{w}\right)$ in the calculation it is possible to estimate the effect 
of dessication upon the volumetric heat capacity of the site soil $\left(C_{s}\right)$ using Eq. (3) [3].

$$
C_{s}\left(\text { cal. } \mathrm{cm}^{-30} \mathrm{C}^{-1}\right)=0.46 X_{m}+X_{w}
$$

This equation was used in conjunction with bulk density and desorption data to estimate the variation of the volumetric heat capacity of the site soil as a function of soil water tension. In addition, the heat pulse diffusivity of the soil was determined at four soil water tensions in the range of field observations. In these tests, as in the desorption testing, the sample was placed in a porous plate extractor. The thermal diffusivity estimates were obtained from temperature measurements at depths of $0.2,1.5$, and $3.0 \mathrm{~cm}$ in a laboratory sample of the site soil held in a porous plate extractor, in which tension was controlled by a hanging water column. The heat pulse was supplied by two infrared lamps mounted $60 \mathrm{~cm}$ above the sample surface. The resulting data were analysed using the scheme of [12]. The resulting data and estimates of tension effects on "thermal admittance" are presented in Table 2.

Table 2. Tension and Soil Thermal Properties

\begin{tabular}{cccc}
\hline $\begin{array}{c}\text { Soil Water Tension } \\
(\mathrm{mm} \mathrm{Hg.)}\end{array}$ & $\begin{array}{c}\text { Heat Pulse } \\
\text { Diffusivity } \\
\alpha_{s}\left(\mathrm{~cm}^{2} \mathrm{sec}^{-1} \cdot 10^{4}\right)\end{array}$ & $\begin{array}{c}\text { Estimated Volumetric } \\
\text { Heat Capacity } \\
C_{s}\left(\mathrm{cal}^{\mathrm{c}} \mathrm{cm}^{-3} \mathrm{o}^{-1}\right)\end{array}$ & $\begin{array}{c}\text { Estimated Thermal } \\
\text { Admittance } \\
\left(C_{s} \sqrt{a_{s}}\right)\end{array}$ \\
\hline 30 & 56 & 0.47 & 3.5 \\
54 & 52 & 0.44 & 3.2 \\
67 & 30 & 0.43 & 2.4 \\
111 & 32 & 0.37 & 2.2
\end{tabular}

The ratio between the maximum and minimum values of the "thermal admittance" estimates in the test range is approximately 1.6. This compares favorably with the ratio of $m$-values of 1.9 , when it is recognized that actual soil water tensions must rise above $120 \mathrm{~mm} \mathrm{Hg}$. in the upper $\mathrm{cm}$ of soil on needle ice nights due to the presence of a normally frozen soil cap above the needles.

These results indicate that the total observed variation in cooling rates could be the product of soil water content variations under the environmental conditions which lead to ground frost and needle growth.

\section{Estimating Feedback Magnitude}

As the radiation boundary conditions have been demonstrated to be statistically similar on the nights in question [11], the major variance in cooling rates (i. e. $m$-values) must be the results of either varia- 
tions in the soil surface "thermal admittance" or wind velocity which would raise the turbulent flux level. At this time there is not

Table 3. Characteristics of Brunt Cooling Periods

\begin{tabular}{cccc}
\hline $\begin{array}{c}\text { Night } \\
\text { (Feb. 1968) }\end{array}$ & $\begin{array}{c}\text { Designation } \\
\text { (for Fig. 6) }\end{array}$ & $\begin{array}{c}\text { Nucleation } \\
\text { Time (PST) }\end{array}$ & $\begin{array}{c}\text { Mean Wind Velocity at } \\
90 \mathrm{~cm} \text { (meters/sec) }\end{array}$ \\
\hline $6-7$ & & & \\
$7-8$ & (a) & 2300 & 1.9 \\
$8-9$ & (b) & 2100 & 0.8 \\
$9-10$ & (c) & 2030 & 0.8 \\
$10-11$ & (d) & 2330 & 1.1 \\
$11-12$ & (e) & 2400 & 0.8 \\
$12-13$ & (f) & 2145 & 0.6 \\
$13-14$ & (g) & 2300 & 0.6 \\
$14-15$ & (h) & 0045 & 0.5 \\
$15-16$ & (i) & 2030 & 1.2 \\
$16-17$ & (j) & 1845 & 1.1 \\
& (k) & 1930 &
\end{tabular}

sufficient data on the covariance of wind velocity and near surface soil water tension during night frost events to definately estimate the frequency of occurrence and magnitude of tension effects on

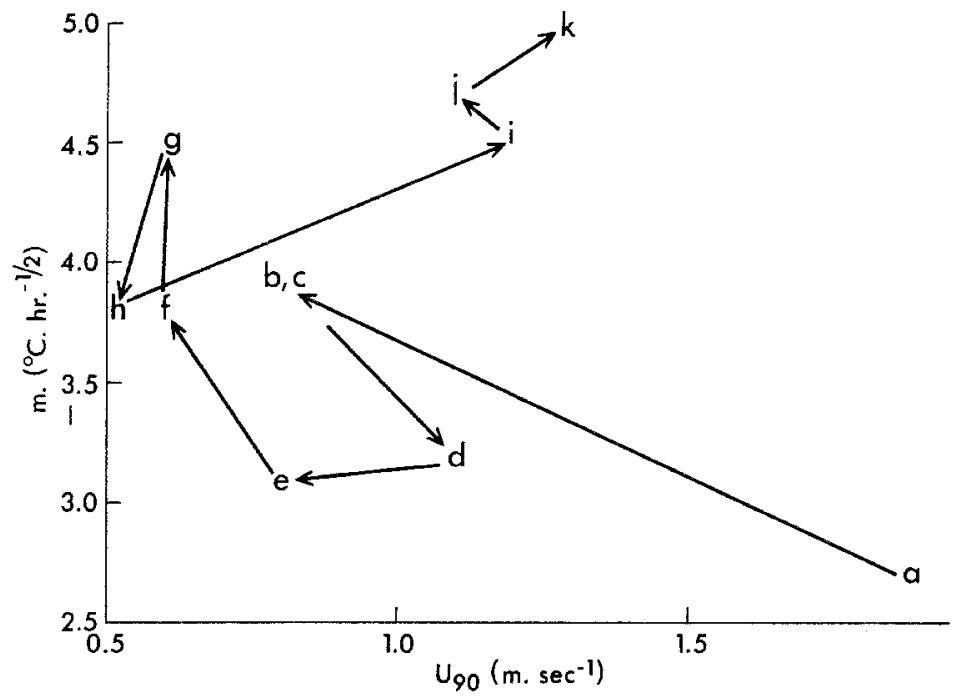

Fig. 6. Cooling Slope - Wind Velocity Diagram (note: arrows indicate temporal sequence)

cooling rates. However, the mean wind velocity between 1600 PST and nucleation (i. e. the period of Brunt cooling) is available on eleven of the nights in question. 
These data indicate that during this needle ice event sequence the wind velocities tended to cluster at approximately 0.7 meters/second on several nights. Mean wind velocity is plotted against the cooling rate (i. e. $m$-values) in Fig. 6 . This diagram strongly suggests that there is no strong correlation or time dependent trend between the two variables and as radiation boundary conditions were relatively static throughout the period, most of the "noise" may result from time dependent variability in the soil thermal properties and the complex interaction between the flow of heat and water in the near surface layers of the soil. Lastly, one persistant reoccurring time dependent pattern in the authors data reinforces this hypothesis.

\section{The "Bump"}

In approximately one third of the approximately thirty nocturnal cooling temperature paterns studied by the author an irregularity on the parabolic Brunt cooling curve occurred during the later phases of cooling prior to nucleation. For lack of a better term it is referred to as the "bump" and is illustrated in Fig. 4 at approximately 2200 PST. Similar "bumps" occur in Funk's data taken during studies of nocturnal cooling in Australia [5]. A detailed examination of the soil temperature data during the night of February 16-17, 1968, indicated the large deviations from the predicted cooling rate occurred at the $5 \mathrm{~cm}$ soil level when the cooling rate was predicted by a finite difference form of Eq. (4).

$$
\partial T / \partial t=\alpha\left(\partial^{2} T / \partial Z^{2}\right)
$$

In this equation the thermal diffusivity is assumed to be static and not influenced by water flow although obviously it must be adjusted for tension dependence. Kinosita et al. [6] have suggested an additional term be added to this equation to inculde the effects of warm water flow from the underlying soil levels to the observation level [see Eq. (5)].

$$
\partial T / \partial t=\underbrace{\alpha\left(\partial^{2} T / \partial Z^{2}\right)}_{\begin{array}{c}
\text { heat flow in } \\
\text { homogeneus medium }
\end{array}}+\underbrace{U_{w}\left(C_{w} / C_{s}\right)(\partial T / \partial Z)}_{\begin{array}{c}
\text { enthalpy change due to } \\
\text { water flow }
\end{array}}
$$

The second term in the equation appeared to be extremely significant during two portions of the night in question. More precisely after nucleation, when warm water is flowing upward toward the freezing plane during needle growth, and during the period of the 
"bump" in the regular parabolic decline of surface temperature, when soil water is flowing upward down the thermal gradient (vapor pressure gradient) toward the cooling surface.

It is therefore probable that water flux "bumps" are not uncommon disturbances during the Brunt cooling of wet medium textured soils during the late evening or early morning hours. Lastly, it should be emphasized that these effects may produce lag and amplitude discrepencies when the analysis of diurnal surface temperature regimes is carried out using equilibrium temperature simulation techniques $[7,9]$, when soil thermal properties are assumed to be static during a diurnal cycle.

\section{Conclusions}

The results of this research may be summarized as follows:

a) The necessity and feasibility of diurnal measurement of soil water tension in the field, using primitive equipment, as a part of soil frost investigations was demonstrated.

b) Two distinct regimes of water flow toward the surface were illustrated during nocturnal frost hazard periods.

c) The existence of lag effects produced by thermal-hydraulic feedback mechanisms was demonstrated to have measurable effects on the state of the frost hazard environment.

\section{Acknowledgements}

The field programme was made possible by grants for graduate research from the University of British Columbia and the National Research Council of Canada through the good offices of Professor J. Ross Mackay, Department of Geography, University of British Columbia, Special thanks is also due Dr. J. De VRIEs,, Department of Soil Physics, University of British Columbia, who constructed the tensiometer used in the field experiments. Miss Joan ENERson, staff cartographer, Department of Geography, University of Michigan, drafted the figures presented in this paper.

\section{References}

1. Brunt, D.: Physical and Dynamical Meteorology. Cambridge University Press, 1934.

2. CARY, J. W.: Water Flux in Moist Soils: Thermal Versus Suction Gradients. Soil Science 100, 168-175 (1965).

3. De Vries, D. A.: Thermal Properties of Soils. In: The Physics of Plant Environment (W. R. vaN WiJk, ed.). North Holland Publishing Co., 1966.

4. De Vries, D. A.: In Site Determination of Physical Properties of the Surface Layer of Field Soils. Soil Science Soc. America Proceed. 33, 349-353 (1969). 
5. Funk, J. P.: Radiative Flux Divergence on Radiative Fog. Quart. Journ. Roy. Met. Soc. 88, 233-249 (1962).

6. Kinosita, S., et al: Formation of Ice Columns on Electrically Heated Ground. Low Temperature Science.

7. Kreith, F.: Principles of Heat Transfer. International, Scranton, Pennsylvania, 1967.

8. Letrau, H.: Problems of Micrometcorological Measurements. In: The Collection and Processing of Field Data (E. F. Bradeey and O. T. Denmead, eds.). CSIRO Symposium, Interscience, 1967.

9. Myrup, L.: A Numerical Model of the Urban Heat Island. Journ. Applied Meteorology 8, 908-918 (1969).

10. Outcalt, S. I.: Weather and Diurnal Frozen Soil Structure at Charlottesville, Virginia. Water Resource Research 5, 1377-1381 (1969).

11. Outcalt, S. I.: A Study of Time Dependence During Serial Needle Ice Events At Vancour, Canada. Arch. Met. Geoph. Biokl., A, 19, 329_337 (1970).

12. VAN $W_{I J K}$, J. R.: General Temperature Variations in a Homogenous Soil. In: The Physics of Plant Environment (VAN WIJK, ed.). North Holland Publishing Co., 1966.

Author's address: Dr. SAm I. Outcalt, The University of Michigan, Geography Department, Ann Arbor, MI 48104, U.S. A. 